\title{
Masting in ponderosa pine: comparisons of pollen and seed over space and time
}

\author{
Kailen A. Mooney $\cdot$ Yan B. Linhart • \\ Marc A. Snyder
}

Received: 2 June 2009/ Accepted: 19 July 2010/Published online: 13 August 2010

(C) The Author(s) 2010. This article is published with open access at Springerlink.com

\begin{abstract}
Many plant species exhibit variable and synchronized reproduction, or masting, but less is known of the spatial scale of synchrony, effects of climate, or differences between patterns of pollen and seed production. We monitored pollen and seed cone production for seven Pinus ponderosa populations (607 trees) separated by up to $28 \mathrm{~km}$ and $1,350 \mathrm{~m}$ in elevation in Boulder County, Colorado, USA for periods of 4-31 years for a mean per site of 8.7 years for pollen and 12.1 for seed cone production. We also analyzed climate data and a published dataset on 21 years of seed production for an eighth population (Manitou) $100 \mathrm{~km}$ away. Individual trees showed high inter-annual variation in reproduction. Synchrony was high within populations, but quickly became asynchronous among populations with a combination of increasing distance and elevational difference. Inter-annual variation in temperature and precipitation had differing influences on seed production for Boulder County and Manitou. We speculate that geographically variable effects of climate on reproduction arise from environmental heterogeneity and population genetic differentiation, which in turn result in localized synchrony.
\end{abstract}

Communicated by Alice Winn.

K. A. Mooney $(\bowtie)$

Department of Ecology and Evolutionary Biology, University of California, Irvine, CA 92697, USA

e-mail: mooneyk@uci.edu

\section{Y. B. Linhart}

Department of Ecology and Evolutionary Biology, University of Colorado, Boulder, CO 80309, USA

M. A. Snyder

Department of Biology, Colorado College,

Colorado Springs, CO 80903, USA
Although individual pines produce pollen and seed, only one-third of the covariation within trees was shared. As compared to seed cones, pollen had lower inter-annual variation at the level of the individual tree and was more synchronous. However, pollen and seed production were similar with respect to inter-annual variation at the population level, spatial scales of synchrony and associations with climate. Our results show that strong masting can occur at a localized scale, and that reproductive patterns can differ between pollen and seed cone production in a hermaphroditic plant.

Keywords Climate forcing - Masting - Spatial autocorrelation $\cdot$ Resource pulse $\cdot$ Wind pollination

\section{Introduction}

For plants reproducing via seed, synchronized reproduction among individuals represents a key strategy for coping with two paramount challenges (Janzen 1976; Kelly and Sork 2002; Silvertown 1980). The first is to ensure proper pollination, and synchrony of reproductive efforts among individuals within populations is important in this regard. The second challenge is to minimize seed loss to the many animals that consume them. Plants cannot escape their seed consumers in space, but they may do so in time by masting, an inter-annual fluctuation in reproduction where seed production is highly variable but also synchronized. Masting has been documented in many species of herbs, shrubs and trees. It appears to provide the dual fitness advantages of increasing fertilization while also reducing herbivory by reducing consumer abundance during years of low reproduction so that their numbers are insufficient to consume all seed during years of high reproduction (e.g., 
Herrera et al. 1998; Kelly and Sork 2002; Kon et al. 2005; Salisbury 1942; Sanguinetti and Kitzberger 2008; Silvertown 1980; and references therein).

Although pollen production is likely an important contributor to masting, there are relatively few studies that address synchrony in pollen production or that compare patterns of synchrony between pollen and seed (but see Sork et al. 1993). Synchrony of pollen production among individuals, as well as synchrony of pollen and ovule production within hermaphroditic individuals, are likely important contributors to synchronized production of seed crops (Kelly and Sork 2002; Norton and Kelly 1988). At the same time, a lower cost of pollen as compared to seed production might lead to more consistent investments in male fitness, lower inter-annual variation and weak correlations between pollen and ovule production within individuals. Although hermaphroditic species might be expected to demonstrate strong synchrony in pollen and ovule production because they are produced by the same individuals, in monoecious species (e.g., many conifers) pollen and ovules are not produced in the same structures, and individual plants may produce primarily pollen or ovules at different ontogenetic stages (e.g., Kon et al. 2005; Krouchi et al. 2004; Linhart and Mitton 1985). Consequently, expectations for inter-annual variation in pollen production for masting species are unclear.

The spatial scale at which masting plant populations are synchronized has a number of important ecological and evolutionary implications. Seeds are concentrated nuggets of nutrition, and many animals have evolved to specialize on or opportunistically consume seeds, and mast years provide pulses of resources that can affect entire communities (Yang et al. 2008). If the spatial scale of plant reproductive synchrony is smaller than the scale of consumer movement, then consumers may recruit to locally abundant resources, entraining these resource pulses into consumer food webs and reducing the efficacy of masting as a strategy for seed predator avoidance (Curran and Leighton 2000; Ostfeld and Keesing 2000). Similarly, the spatial scale of increase in consumer abundance will have implications for whether or not the predators of seed consumers can recruit and pass these resource pulses up to higher trophic levels (Lithner and Jonsson 2002). Widespread synchrony may also reduce pollen limitation in wind-pollinated species (Norton and Kelly 1988; Tapper 1996), increase longdistance gene flow and reduce local adaptation (Iwasa and Satake 2004). The spatial scale of synchrony is thus a key aspect of the ecology and population biology of masting plants.

Despite many examples of masting, there are relatively few studies of the spatial scales at which such synchronized reproduction occurs. Most studies have documented synchrony over relatively large $(>100 \mathrm{~km})$ areas (Bock and Lepthien 1976; Koenig and Knops 1998, 2005; Monselise and Goldschmidt 1982; Poncet et al. 2009; Sanguinetti and Kitzberger 2008; Schauber et al. 2002; Waller 1993) but a few studies have found only localized synchrony, and these examples come from both temperate (Lamontagne and Boutin 2007; Yasaka et al. 2003) and tropical (Cannon et al. 2007; Wich and Van Schaik 2000) forests. Synchronicity across large areas is often associated with inter-annual climatic variation, where variable weather provides important resources, stimuli or limitations that drive patterns of reproduction (e.g., Post 2003; Sanguinetti and Kitzberger 2008; Schauber et al. 2002). In such cases, it can be challenging to separate climate as a driver of masting versus climate simply providing the cues for masting that is driven by other ecological factors such as predator satiation (Ashton et al. 1988; Tapper 1996). In addition, masting is predicted to occur entirely via so-called pollen coupling where inter-annual variation is driven by the physiological costs of reproduction, and synchrony occurs because out-cross pollen limitation renders asynchronous reproduction unsuccessful (Iwasa and Satake 2004; Satake and Iwasa 2002).

The objectives in the current study were to investigate patterns of synchrony, temporal variability and spatial autocorrelation in ponderosa pine (Pinus ponderosa var. scopulorum) in the Colorado Front Range. Where most masting studies have focused exclusively on seed or flower production, we document patterns of both pollen cone and seed cone production in this monoecious species. We collected long-term data on pollen and seed cone production from 607 trees in seven pine populations dispersed across $200 \mathrm{~km}^{2}$ and an elevational gradient of $1,350 \mathrm{~m}$ in the Colorado Rockies. We then compared our reproductive data to local climatic data and to data on pine reproduction from a more distant site (Shepperd et al. 2006). With these data we addressed the following questions:

1. How synchronized and variable is reproduction within each population, and how do our observations compare to values for the species from elsewhere in its range (Herrera et al. 1998)?

2. How much synchrony is there among populations, and does increasing distance and elevational difference among sites influence synchrony?

3. What is the influence of local climate on patterns of reproduction, and are such relationships consistent between sites?

4. How do pollen and seed production compare with respect to spatial patterns of synchrony and the influence of climate? 


\section{Materials and methods}

Pine, field sites and data collection

Ponderosa pine is a monoecious conifer with a reproductive cycle spanning more than 2 years. The meioses that lead to pollen and egg production occur in the summer of year 0 and release of pollen from male strobili occurs approximately in the spring of year 1. Female strobili develop into seed cones in the spring of year 2, and these small seed cones reach their full size by mid-summer at which point healthy seed cones are large and usually green. Seed release occurs several months later in the fall.

We monitored pollen and seed cone production from seven populations in the foothills of Boulder County, Colorado, USA that spanned an elevational range of $1,700-3,050 \mathrm{~m}$ (Table 1). This area is very heterogeneous in terms of climate, soils, and biotic communities (Mutel and Emerick 1992). The studied populations occupied very different habitats, ranging from prairie (Marshall) to the lower Montane zone (Boulder Canyon and Enchanted Mesa) to the upper Montane zone (Bald Mountain and Sugarloaf) to mixed-conifer subalpine forest (Niwot) in a distance of just $25 \mathrm{~km}$. Mean annual precipitation across these population's ranges from a low of $400 \mathrm{~mm}$ at Marshall to a high of $800 \mathrm{~mm}$ at Niwot.

In addition, we obtained seed production data from Shepperd et al. (2006) for the Manitou Experimental Forest (Manitou) in Woodland Park, Colorado at an elevation of 2,500 m (Table 1). Whereas Manitou is approximately $100 \mathrm{~km}$ from the closest Boulder County populations, the most distantly situated Boulder County populations (Marshall and Niwot) are separated by only $28 \mathrm{~km}$. Because the seven Boulder County populations are dispersed across an elevational gradient, there is a strong correlation between Euclidian distance and elevational difference among populations ( $r=0.87$ ). The forest structure for the eight study populations is characterized by large, mature stands of widely spaced pines. Annual precipitation at the Boulder Canyon site during the course of our study was $520 \pm 20 \mathrm{~mm}$ annually (1977-2008), while Manitou was drier at $420 \pm 20 \mathrm{~mm}$ annually (1981-2001). At these sites, pine seed cones and seeds are fed upon primarily by several specialist herbivores, including the moths Eucosma sp. and Dioryctria auranticella, the weevil Conotrachelus neomexicanus and the cone beetle Conophthorus ponderosae, all of which are endemic to ponderosa pine forests (Bodenham and Stevens 1981; Hedlin et al. 1980). Squirrels (Sciurus niger at Boulder, and Sciurus aberti at Enchanted Mesa, Betasso, and Bald Mountain) and crossbills (Loxia curvirostra) are also periodic cone predators.

All data on pollen and seed cone production are based on counts made of multiple individual trees at each site.

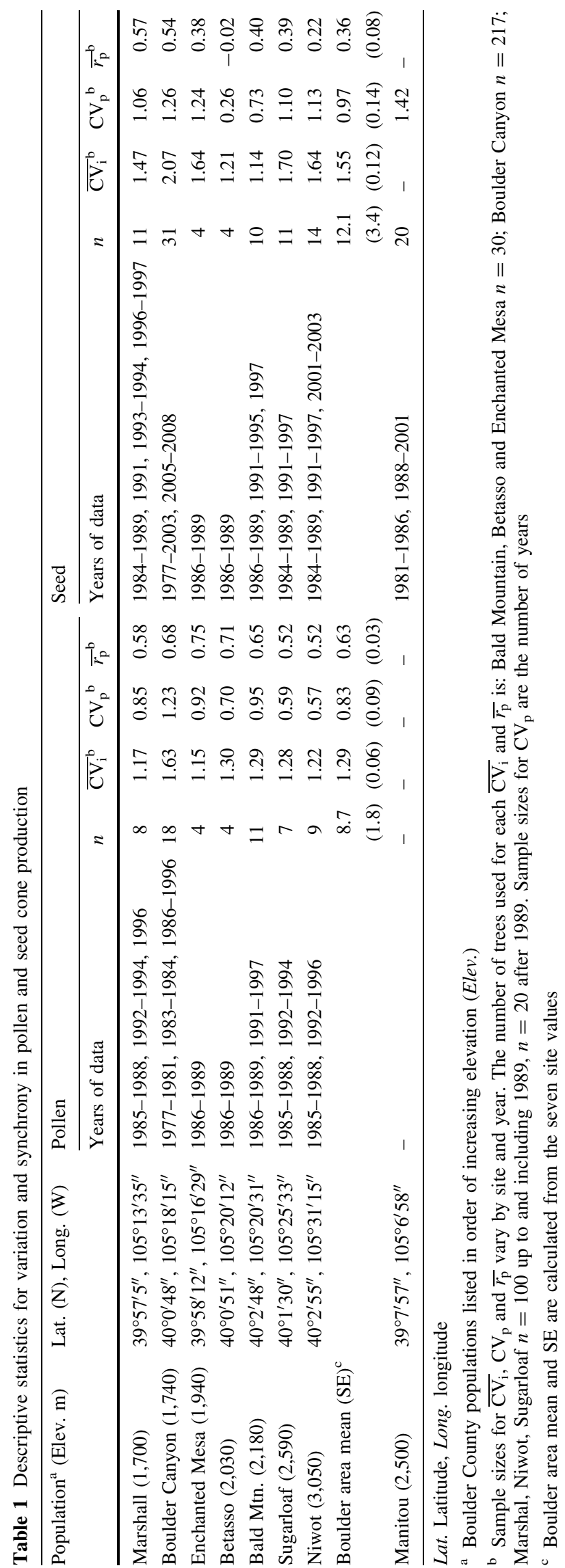


In these forests, trees are relatively small (15 m or less) and grow in open stands, usually on steep slopes. For these reasons, whole crowns are easily visible, and branch tips with cone clusters or bright yellow pollen strobili can be counted readily. The years of data collection differed among populations and for pollen and seed data, ranging 4-31 years for a mean per site of 8.7 years for pollen and 12.1 for seed cone production (Table 1). The number of trees measured also varied based on population and sampling year, ranging from 20 to 217 trees (Table 1). Pollen production was quantified each June by counting the number of branch tips on a tree with male strobili, while individual seed cones were counted on each tree between July and October. One or more of the authors was present for all counts to ensure continuity and consistency of data collection.

These two sources of data are taken as surrogates for direct measurements of gamete production, such that the number of fertilized ovules is estimated from seed cone counts and the number of pollen grains from counts of pollen-bearing branch tips. Pollen-bearing branch tip counts might be expected to mask more variation as compared to seed cone counts because a branch tip is surrogate for many more pollen grains than a cone is for ovules. Yet counts were lower for seed cones than for pollen-bearing branch tips, with count means $( \pm \mathrm{SE})$ of $26.4 \pm 0.8$ (range $0-1,267 ; n=9,468$ counts) and $139+3$ (range $0-2,779 ; n=5,940$ counts), respectively, such that a single seed cone is surrogate for a greater proportion of investment in female function than a pollenbearing branch tip is for investment in male function. Consequently, whether or not these differing surrogates bias comparisons of variability in male and female investment in reproduction, and the likely direction of such bias, is unclear.

\section{Variability and synchrony}

To assess synchrony and variability of reproduction we used four approaches. First, we estimated mean individual synchrony within each population $\left(\bar{r}_{\mathrm{p}}\right)$ by calculating Pearson's correlation coefficients for reproduction between all pairs of trees across years, and then averaging these values to a single estimate for the population. Second, we estimated mean individual variability $\left(\overline{\mathbf{C V}}_{\mathrm{i}}\right)$ for each population by calculating the coefficients of variation $(\mathrm{CV})$ for seed and pollen cone production for each individual across years and then calculating a population average. Third, we estimated the population variability $\left(\mathrm{CV}_{\mathrm{p}}\right)$ for each population defined as the $\mathrm{CV}$ across years of the mean seed and pollen cone production for all individuals. While all three statistics were calculated for each Boulder County population, only $\mathrm{CV}_{\mathrm{p}}$ could be calculated for Manitou as data were not available for individual trees (Shepperd et al.
2006). And finally, fourth, we calculated the mean withinindividual correlation of pollen (year $x$ ) and seed cone (year $x+1$ ) production for Boulder Canyon based upon 217 trees and 18 years of data.

To quantify the scale of spatial autocorrelation in reproductive synchrony, we calculated the Pearson's correlation coefficient for reproduction across years between all pairs of trees, and then averaged these values between each pair of Boulder County populations as an estimate of between-population synchrony $\left(\overline{r_{\mathrm{ap}}}\right)$. This statistic is thus identical to that of $\overline{r_{\mathrm{p}}}$ (described above) except that it is based on correlations of trees between (vs. within) populations. In addition to these 21 between-population values, we also calculated a single within-population mean correlation. We then correlated $\overline{r_{\mathrm{ap}}}$ with the Euclidian distance and the difference in elevation between populations, testing for their significance with a Mantel test. Manitou was not included in this analysis because seed production values for individual trees were not available.

\section{Climate analyses}

We measured the association between climatic fluctuations and reproduction for Boulder Canyon and Manitou, the two populations with the longest datasets. Climate data for the Boulder Canyon population came from the Colorado Climate Center in the Department of Atmospheric Science at Colorado State University (http://ccc.atmos.colostate.edu/, site $=$ Boulder 50848) while those from Manitou came from a climate station at the Manitou Experimental Forest. The Boulder climate station is located $3.9 \mathrm{~km}$ distant and $20 \mathrm{~m}$ lower in elevation than the Boulder Canyon population, while the Manitou climate station is located $3.7 \mathrm{~km}$ distant $15 \mathrm{~m}$ lower in elevation than the Manitou population. We related total monthly precipitation and monthly mean temperature to seed or seed cone production (Manitou and Boulder Canyon, respectively) and pollen production (Boulder Canyon only) by correlating population reproduction with each monthly climatic variable for the 3year period prior to cone production (i.e., 36 correlations), and plotted these monthly correlation coefficients against time. Inspection of these plots allowed us to graphically assess which variables at which time points have the largest influence on pine reproduction. We took this graphical approach because of the prohibitively low power associated with formally correcting for type I error with such a large number of comparisons (Garcia 2004). Based upon these separate analyses of Boulder Canyon and Manitou, we then tested for population differences for the association between seed production and climatic variables.

Our initial analyses were based upon the raw monthly climate data provided by the Colorado Climate Center, but we found the patterns of association with pine reproduction 
to be highly volatile and difficult to interpret. In contrast, analyses based upon 3-month running averages of each climatic variable (i.e., the value used for January precipitation is the average of November, December and January) provided clear patterns of association, and this is the approach we present here. We speculate that this lack of a clear association between reproduction and short-term climate data arises from the extreme day-to-day variation that can occur in this region (e.g., daily temperature fluctuations of as much as $30^{\circ} \mathrm{C}$ ). While 3-month running averages do not allow us to detect the role of potentially important but short-term climatic events (Ashton et al. 1988), they do characterize the relationship between reproduction and longer term or seasonal climate trends (Norton and Kelly 1988; Poncet et al. 2009).

\section{Results}

\section{Variability and synchrony}

Within each population, reproduction was both variable among years and synchronized within years (Table 1). $\overline{\mathrm{CV}_{i}}$ for the seven Boulder County populations, quantifying mean variability of individual trees, ranged from 1.15 to 1.63 for pollen cones and from 1.14 to 2.07 for seed cones. $\mathrm{CV}_{\mathrm{p}}$, the population level variability, ranged from 0.57 to 1.23 for pollen and 0.26 to 1.26 for seed in Boulder County, with Manitou exceeding this range substantially at a value of 1.42. A two-way ANOVA testing for the main (but not interactive) effects of cone type (pollen vs. seed) and population on reproductive $\mathrm{CV}$ showed that pollen was less variable than seed cones with respect to $\overline{\mathrm{CV}_{i}}\left(F_{1,6}=2.52\right.$, $P=0.04)$ but not for $\mathrm{CV}_{\mathrm{p}}\left(F_{1,6}=0.97, P=0.36\right)$. There was no detectable relationship between elevation and seed cones with respect to $\mathrm{CV}_{\mathrm{p}}(r=0.06, n=7, P=0.90)$ and pollen and seed cones with respect to $\overline{\mathrm{CV}_{i}}$ (pollen, $r=$ $-0.27, \quad n=7, \quad P=0.52 ; \quad$ seed, $\quad r=-0.03, \quad n=7$, $P=0.94)$ while there was some indication that pollen $\mathrm{CV}_{\mathrm{p}}$ decreased with elevation $(r=-0.75, n=7, P=0.0511)$.

Among the seven Boulder County populations, the mean individual synchrony, i.e., $\overline{r_{\mathrm{p}}}$ the mean of all pairwise Pearson's correlation coefficients between individuals within each population, ranged from 0.52 to 0.75 for pollen cones and 0.22 to 0.57 for seed cones, with the Betasso population standing out for being exceptionally unsynchronized at a value of -0.02 . Comparing $\overline{r_{\mathrm{p}}}$ for pollen and seed cones, the former was significantly more synchronized $\left(F_{1,6}=9.77, P=0.02\right)$, and this remained true if Betasso was excluded $\left(F_{1,5}=13.95, P=0.01\right)$. There was no detectable relationship between $\overline{r_{\mathrm{p}}}$ and elevation for either pollen $(r=-0.60, n=7, P=0.10)$ or seed cone $(r=$ $-0.40, n=7, P=0.37$ ) production. As for synchrony between pollen and seed cone production within individual trees, there was a significant and positive within-tree correlation for the Boulder Canyon population $\left(r^{2}=0.32 \pm\right.$ 0.02 ; mean $\pm 1 \mathrm{SE})$.

The among-population synchrony in pollen and seed cone production $\overline{r_{\text {ap }}}$ was relatively strong between geographically proximate populations, but declined quickly with Euclidian distance and elevational difference, although the association between seed cone production and distance was marginally non-significant (Fig. 2). For pollen cone production, $\overline{r_{\mathrm{ap}}}$ was reduced by $50 \%$ at values of $10.5 \mathrm{~km}$ and $700 \mathrm{~m}$ and reached zero at values of $21 \mathrm{~km}$ and $1,400 \mathrm{~m}$. For seed cone production, $\overline{r_{\mathrm{ap}}}$ was reduced by $50 \%$ at values of $13.5 \mathrm{~km}$ and $550 \mathrm{~m}$ and reached zero at values of $27 \mathrm{~km}$ and $1,100 \mathrm{~m}$. Distance was a stronger predictor of $\overline{r_{\mathrm{ap}}}$ than elevation for pollen cones, but the effects of distance and elevation were similar for seed cones. There was no detectable synchrony in seed cone production between Boulder Canyon and Manitou populations $(r=-0.23, n=20, P=0.33)$.

\section{Climate analyses}

Our graphical analysis shows that pollen and seed cone production are each correlated in nearly identical ways to climate at the Boulder Canyon population (Fig. 3a, b). In both cases, reproduction was positively associated with a cool spring (May-July) in year $x-2$ (i.e., the summer 1 year prior to pollen cone production and 2 years prior to seed cone production), a wet summer (July-September) in year $x-2$ and a warm winter (December-February) in year $x-1$. Our graphical analyses show a weaker link between climate and reproduction at Manitou (Fig. 3c, d); reproduction was positively correlated with a wet spring (February-April) and a warm summer (May-August) in year $x-2$, as well as a wet spring (March-May) in year $x-3$.

Our graphical approach of associating reproduction and climate was based upon 36 correlations for each comparison of reproduction (pollen or seed cone production) with climate (temperature or precipitation). As a complementary approach, we also used factor analysis to summarize these 36 inter-related climate variables into a smaller number of orthogonal factor scores. We used the SAS procedure FACTOR (SAS Institute 2008) and selected the number of factors to retain by inspecting scree plots as described by Johnson (1998). For each analysis, between 11 and 13 factors explained $85 \%$ or more of the variance in the original climate data (Boulder Canyon precipitation, 13 factors, $85 \%$ variance explained; Boulder Canyon temperature, 13 factors, $91 \%$ variance explained; Manitou precipitation, 13 factors, $91 \%$ variance explained; Manitou temperature, 11 factors, $86 \%$ variance explained). At each site, pollen and seed production were significantly 
$(P<0.05)$ correlated with either one or two of these factors. By inspecting which of the original climatic variables loaded most strongly on the factors correlated with reproduction, we found relationships between reproduction and climate identical to those revealed by the graphical approach (Fig. 3). Consequently, the relationships between climate and reproduction drawn from correlations with 36 separate climatic variables (Fig. 3) also hold when these analyses are repeated with far fewer (11-13) separate statistical tests. For Boulder Canyon, six of the 52 correlations performed were significant which is statistically unlikely to occur by chance alone $(P=0.03$, binomial expansion test) while only four of 48 correlations were significant for Manitou $(P=0.12$, binomial expansion test).

To formally compare the relationship between climate and seed (Manitou) or seed cone (Boulder Canyon) production at the two populations, we constructed a dataset of seed production and the three climatic variables associated with reproduction at Boulder Canyon. We chose the Boulder Canyon climate variables because of the apparently stronger association between climate and reproduction observed at this site (see above). Because of the inherent inter-relation among these three climatic variables, we performed a factor analysis to reduce these three climate variables to a single variable ("climate score") using the SAS procedure FACTOR. Climate score explained $59 \%$ of the multivariate variation in the three component variables. Using the original climate data from each site, we then calculated the climate score separately for each year for Boulder Canyon and Manitou in order to separately relate cone production to inter-annual climatic variation. We compared the relationship between climate score and reproduction between the two populations using analysis of covariance, where seed (or seed cone) production was modeled as a function of climate score, population and their interaction. This analysis showed a significant population-by-climate score interaction $\left(F_{1,46}=5.07\right.$, $P=0.03$ ), with climate score being significantly associated with reproduction at Boulder Canyon but not Manitou.

\section{Discussion}

The principal conclusions to be drawn from the results of our analyses are:

1. There was high inter-annual variability and synchrony in both pollen and seed cones within populations (Table 1; Fig. 1).

2. Synchrony among populations occurred at a relatively small spatial scale, declining to asynchrony over distances of less than $28 \mathrm{~km}$ or elevational differences of less than 1,400 m (Fig. 2).
3. There was a strong association between climate and reproduction at Boulder Canyon, less so at Manitou, and the relationship between climate and reproduction differed between the two populations (Fig. 3).

4. Although individual pines produce both pollen and seed cones, only one-third of the covariation within trees was shared, and patterns of variability and synchrony differed; pollen showed stronger withinpopulation synchrony at all sites and inter-annual variation was lower at the level of the individual tree (Table 1). At the same time, pollen and seed cone production were similar with respect to inter-annual variation at the population level (Table 1), their spatial and elevational scales of synchrony and associations with climate (Fig. 3).

We discuss each of these results and their implications in turn.

Within- and among-population variation and synchrony

We found high inter-annual variability and synchrony within the seven Boulder County populations (Table 1). The level of inter-annual variability we show for ponderosa pine is somewhat lower than values observed elsewhere; excluding reports from Colorado by Linhart (1988) and Linhart and Mitton (1985), seven studies on this species reviewed by Herrera et al. (1998) report a mean $( \pm 1 \mathrm{SE})$ $\mathrm{CV}_{\mathrm{p}}$ of $1.21 \pm 0.10$, a value much greater than the mean value of $0.97 \pm 0.14$ we show here for Boulder County (Table 1). Likewise, our values are somewhat smaller than values for seeds or cones in forest trees generally; Kelly and Sork (2002) report a mean $\mathrm{CV}_{\mathrm{p}}$ of 1.25 for forest trees and 1.16 for abiotically pollinated and dispersed plants. While other studies have noted an increase in population variability with elevation (e.g., Webb and Kelly 1993), we found mixed evidence for an influence of elevation in that there was either no relationship (pollen and seed cones for $\overline{\mathrm{CV}}_{\mathrm{i}}$ and pollen for $\mathrm{CV}_{\mathrm{p}}$ ) or that variability was lower at high elevation sites (seed for $\mathrm{CV}_{\mathrm{p}}$ ). Nevertheless, there were sizable differences among the seven Boulder County populations in both variability $\left(\overline{\mathrm{CV}_{\mathrm{i}}}, \mathrm{CV}_{\mathrm{p}}\right)$ and synchrony $\left(\overline{r_{\mathrm{p}}}\right)$ (Table 1$)$, demonstrating that masting patterns need not be characteristic of species (Herrera et al. 1998; Silvertown 1980; Tapper 1996; Waller 1993) but rather are an interaction between genetically based species traits, which may or may not vary spatially, and local site conditions including weather.

The relatively localized scale of synchrony we show for ponderosa pine in Boulder County (Fig. 2) is very different from the large spatial scales (greater than $100 \mathrm{~km}$ ) documented for many other species (Kelly et al. 2008). Synchrony among populations for pollen cones showed clear 

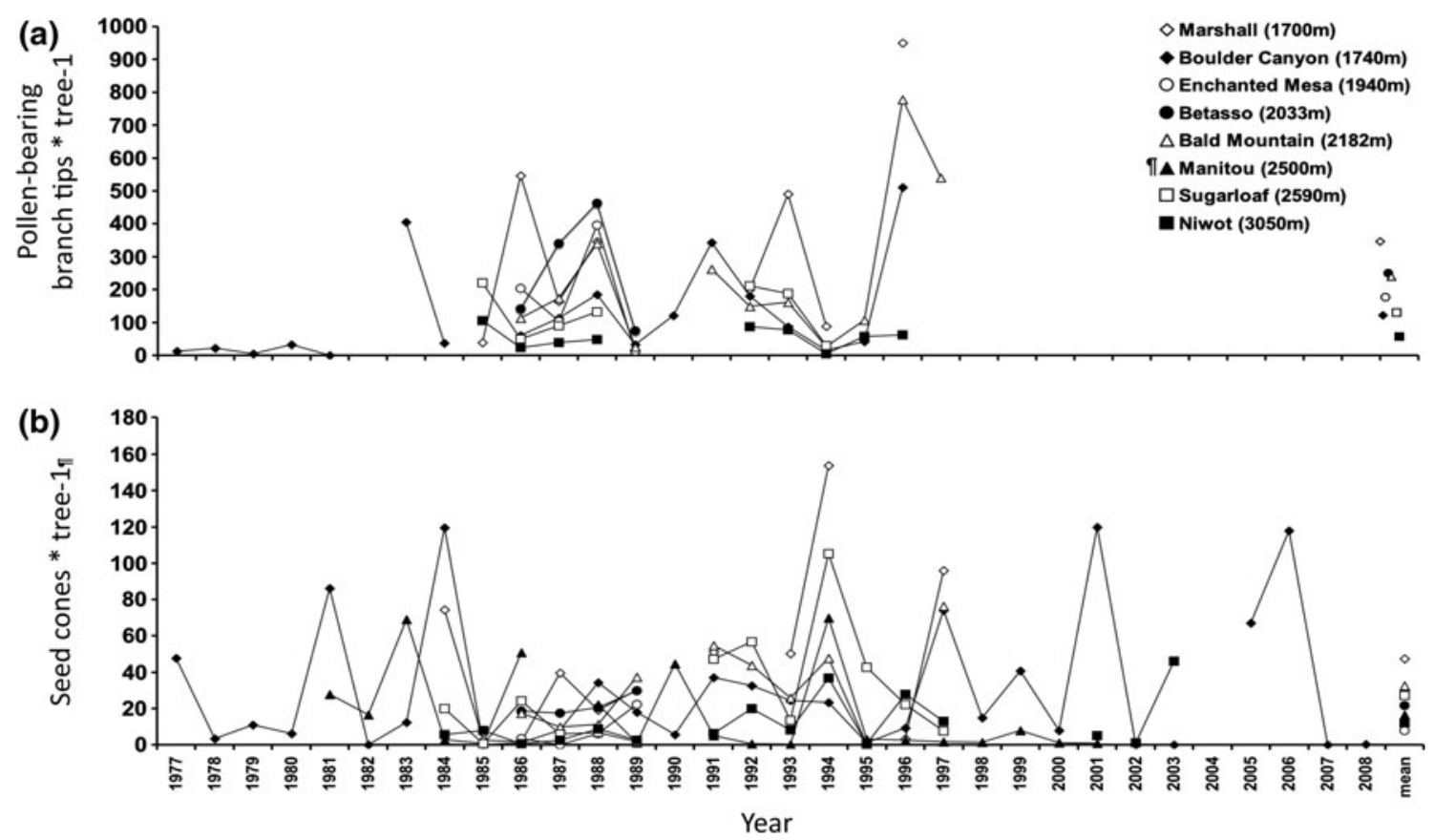

Fig. 1 Annual estimates of reproduction for seven Boulder County populations and one Manitou experimental forest population from Shepperd et al. (2006). a Mean pollen cone production and b seed cone production per tree. For Manitou, only seed production data are presented and data are expressed as seeds $\mathrm{ha}^{-1} \times 10^{-1}$ instead of seed cones per tree. See Table 1 for sample sizes. Error bars are omitted for clarity
Fig. 2 Correlation coefficients $(r)$ between pairs of Boulder County populations for a, b pollen cone production and $\mathbf{c}$, d seed cone production in relation to a, c Euclidian distance between these pairs of populations and $\mathbf{b}, \mathbf{d}$ the difference in elevation. Each pairwise $r$ is the mean of all pairwise correlations between trees at two populations $\left(\overline{r_{\mathrm{ap}}}\right)$. Each correlation coefficient at a distance of zero is the mean of the seven within-population correlation coefficients $\left(\overline{r_{\mathrm{p}}}\right)$. a-d The $r$ for the relationship between distance, Euclidian distance and cone production are given in the bottom-left corner with significance levels determined by Mantel tests
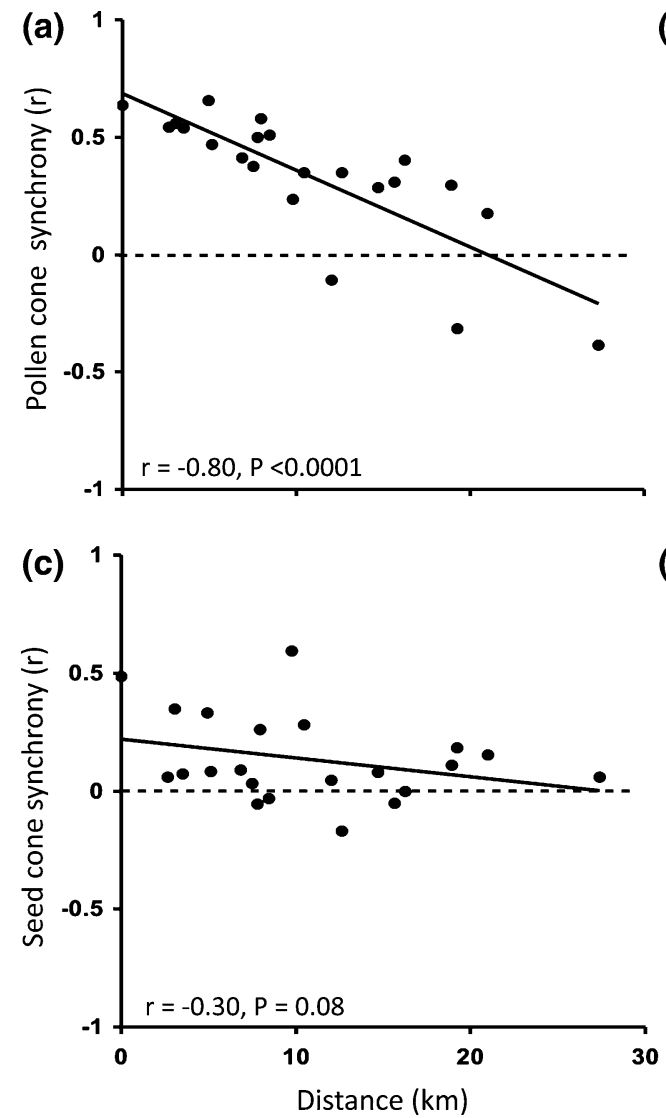

(b)
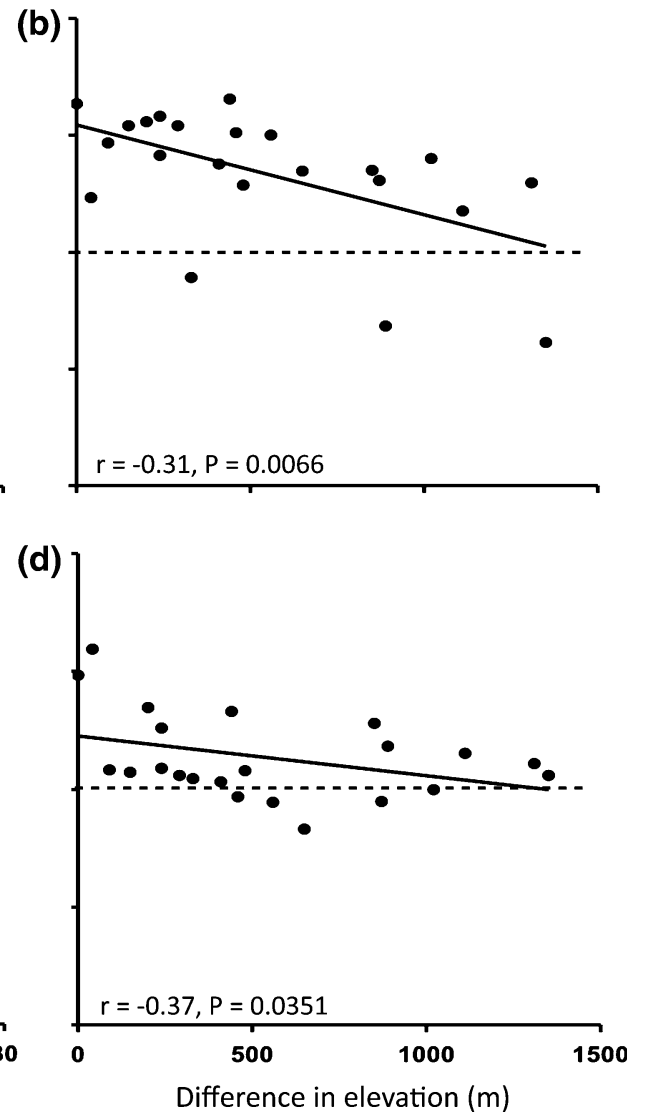

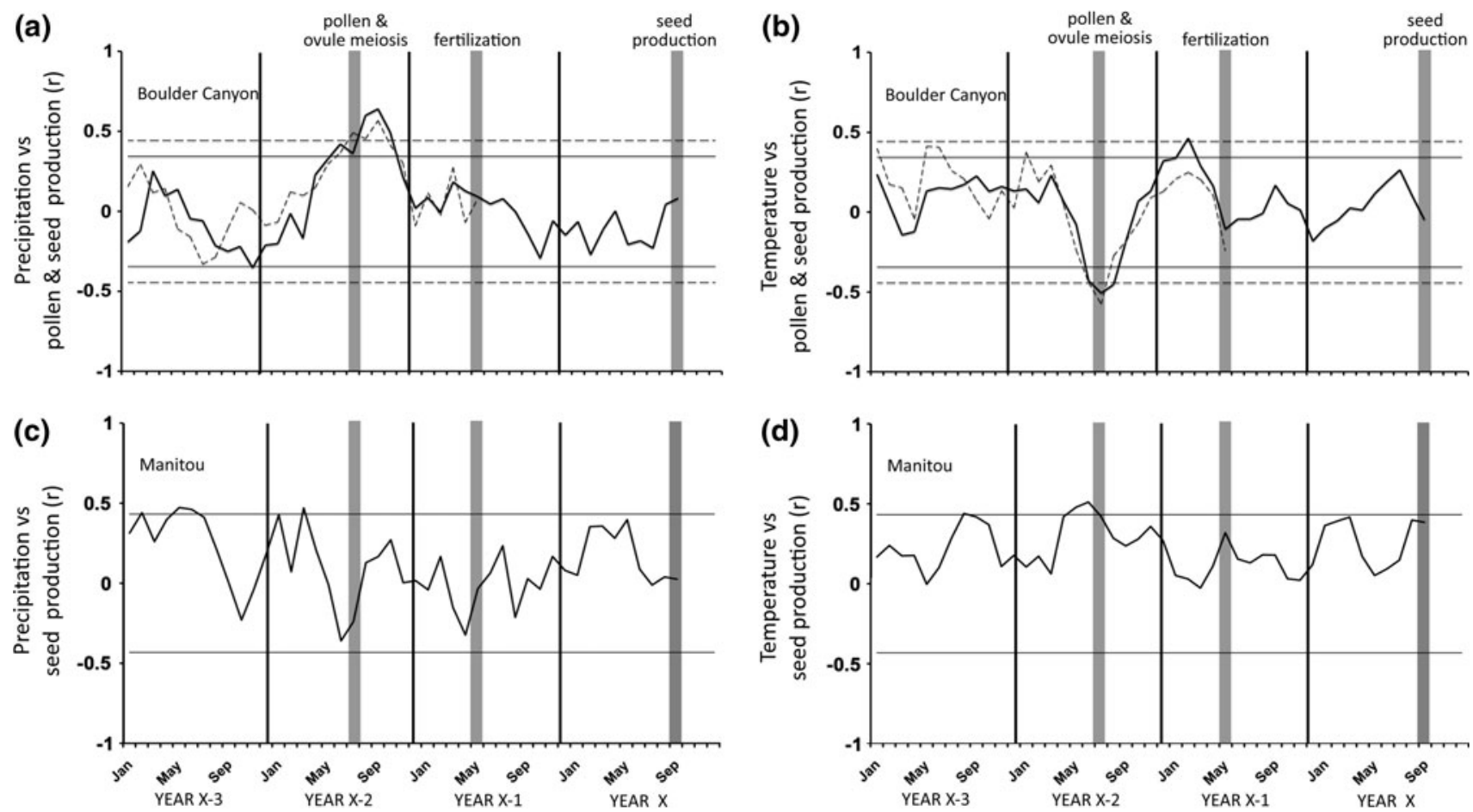

Fig. 3 Correlation coefficients between monthly climatic variables and seed cone or seed production (solid lines seed cones and seeds counted in fall of year $x$ ) and pollen cone production (dashed line pollen cones counted in spring of year $x-1$ ) in the years prior to seed cone and pollen production at $\mathbf{a}, \mathbf{b}$ Boulder Canyon and $\mathbf{c}, \mathbf{d}$ Manitou. The climate variables used in these analyses are running averages of the month indicated and the two preceding months. Pollen coneclimate and seed cone-climate correlations at Boulder Canyon are

declines with increasing elevational difference and distance, while seed cones showed significant decline with increasing elevational difference but the association with distance was marginally non-significant. Given the strong correlation between elevation difference and Euclidian distance among our populations $(r=0.87)$ it is impossible to disentangle the relative importance of these two factors. Masting across large spatial scales has also been found for many other plants, including Araucaria in Argentina (Sanguinetti and Kitzberger 2008), various oaks (Koenig and Knops 2005; Waller 1993), several species of boreal forest trees (Bock and Lepthien 1976; Koenig and Knops 1998), multi-species synchrony associated with El Niño events in New Zealand (Schauber et al. 2002), the biennial fruiting patterns in fruit trees noted by Monselise and Goldschmidt (1982) and the regional patterns of Larix decidua in several adjacent valleys of the French Alps (Poncet et al. 2009). However, very localized synchrony has also been found in several species (Cannon et al. 2007; Lamontagne and Boutin 2007; Wich and Van Schaik 2000; Yasaka et al. 2003). So while masting at a grand scale may be common (Kelly et al. 2008), our own results again

based upon 18 and 31 years of data, respectively. Seed-climate correlations for Manitou are based on 19 years of data. With these sample sizes, correlation coefficients are significant $(P=0.05$, unadjusted for multiple comparisons) at Boulder Canyon for pollen and seed cone production at values of \pm 0.33 and \pm 0.44 , respectively, and at Manitou for seed production at values of \pm 0.43 . These thresholds for significance are indicated with horizontal solid lines for seed cones and seeds and horizontal dashed lines for pollen cones

demonstrate that strong but localized masting patterns can also occur.

The notable lack of regional synchrony in pine reproduction in Boulder County may reflect, at least in part, the regional heterogeneity in environmental conditions. Boulder County is characterized by steep environmental gradients, rising $1,350 \mathrm{~m}$ in elevation in just $25 \mathrm{~km}$ and, in so doing, transitioning from prairie to montane to alpine habitats. This variable landscape has produced significant genetic differentiation among several of the populations studied here (Mitton et al. 1977, 1980), as well as strong geographic variation in the communities of insects that are the primary consumers of seed cones at our populations and are known to have very localized movement (Bodenham and Stevens 1981; Hedlin et al. 1980; Keefover-Ring and Linhart 2010).

\section{Effects of climate}

Population-specific relationships between climate and seed production may also contribute to the lack of regional synchrony. Although sites were separated by only $100 \mathrm{~km}$, 
we found that the local relationships between temperature and precipitation and seed production varied between Manitou and Boulder Canyon (Fig. 3). Masaki et al. (2008) also found strong but population-specific influences of climate upon Fagus crenata reproduction in mountainous terrain and speculated that population genetic differences may be responsible. Poncet et al. (2009) found that Larix populations at different elevations also responded to different climate cues, and attributed the differences to variable physiology. Reproduction at Boulder Canyon was associated with cool springs, wet summers and warm winters in the 12 months leading up to pollen and ovule production, whereas at Manitou it was associated with wet springs and warm summers in the 12 months leading up to pollen production, as well as wet springs 24 months prior. While our use of 3-month running averages in this analysis undoubtedly obscures the influences of potentially important short-term climatic events (Ashton et al. 1988), this approach nevertheless documents the importance of longer-term (seasonal) climatic fluctuations (Norton and Kelly 1988; Poncet et al. 2009). The extent to which these differences are due to population genetic variation or geneby-environment interactions is unclear. In contrast, Krannitz and Duralia (2004) observed associations between temperature and ponderosa pine reproduction in California and Washington states that were similar to each other and to the pattern we observe for Manitou. Regardless of the basis for the differences seen between Boulder Canyon and Manitou, we speculate that environmental heterogeneity and steep environmental gradients lead to population-specific effects of climate, and that this in turn contributes to the small scale of reproductive synchrony that we have observed.

\section{Comparison of pollen and seed cones}

Although individual pines can produce both pollen and ovules, more than two-thirds of the covariation within individual trees was not shared $\left(\overline{r^{2}}=0.32\right)$. Past work in ponderosa pine (Linhart and Mitton 1985) and other plants (Klinkhamer et al. 1997) including conifers (Kon et al. 2005; Krouchi et al. 2004) has shown that smaller individuals produce mostly pollen and larger ones ovules and seed. Such ontogenetic shifts in investment in male and female function may thus decouple synchrony in pollen and seed production. Our results show that even in hermaphroditic species, patterns of investment in female and male function need not be made in parallel. Indeed, a full understanding of masting thus requires documenting patterns of investment not only in seed, but pollen as well.

While numerous studies have documented masting patterns for seed production, our data provide a rare example of such data for both seed and pollen simultaneously. Individual trees were significantly less variable $\left(\overline{\mathrm{CV}_{\mathrm{i}}}\right)$ and more synchronized $\left(\overline{r_{\mathrm{p}}}\right)$ for pollen as compared to seed cone production (Table 1), but did not differ significantly with respect to population-level variation $\left(\mathrm{CV}_{\mathrm{p}}\right)$. Consequently, lower individual variation coupled with greater synchrony led to levels of population variation for pollen that were similar to that of seed cones. The lower individual variability in pollen production is consistent with the hypothesis that trees may consistently invest in less costly male function even in years of low investment in ovule and seed production. This can be thought of as an optimistic male strategy of always producing at least some pollen in case ovules are available. At the same time, variation in production of mature seed cones is a product of variation in both ovule production and pollination rates, as well as early loss of developing cones. Without data on ovule production, we cannot determine whether the more variable patterns observed in seed cones is due to differential patterns of investment in male and female function, or alternatively whether this pattern is simply an outcome of seed production being the product of two separate and individually variable processes.

Despite notable differences between pollen and seed cones for patterns of variability and synchrony, each was associated with climate in a nearly identical fashion (Fig. 3). This may be attributed in part to the fact that seed cone production itself may be driven by pollen availability. Evidence for pollen limitation in ponderosa pine comes from work by McDonald (1992) showing a strong relationship ( $r^{2}=0.76$ ) between the proportion of viable seed and total cone production, and we have observed a similar relationship (Y. B. Linhart, unpublished data). The association between climate and seed cone production is thus likely driven by both a direct effect on ovule production, but also an indirect effect via pollen availability. The parallel response of pollen and seed cone production to climate must also be strengthened by the fact that both are produced within individual trees. Yet because two-thirds of the covariation in pollen and seed cone production within individual trees was uncorrelated, climate must also influence pollen and seed cone production somewhat independently, but in an equivalent fashion.

\section{Conclusion}

The scale of synchrony in dominant plants carries important ecological and evolutionary implications. Masting can increase seed survival by alternately starving and satiating consumers (Janzen 1976; Kelly and Sork 2002; Silvertown 1980), but only if the spatial scale of masting is greater than that of consumer movement. Likewise, whether these resource pulses are entrained into local food webs may depend on whether consumers can dynamically move 
among unsynchronized populations (Curran and Leighton 2000; Lithner and Jonsson 2002; Ostfeld and Keesing 2000; Yang et al. 2008). From an evolutionary perspective, patterns of inter-population synchrony have implications for pollen limitation and seed set (Iwasa and Satake 2004), gene flow and localized adaptation (Mitton et al. 1977; Mitton et al. 1980).

Determining the commonness of large- versus smallscale synchrony-and the factors responsible for each-is important given the consequences of masting scale outlined above. While many surveys show synchrony at large scales, there are also examples of strong but localized synchrony (cf. "Introduction"). Accurately determining the distribution of scales at which masting occurs may be influenced by publication bias if widespread synchrony is more apparent (or more often studied) than is a lack of synchrony. Multiple interacting factors almost certainly control masting scale, and we propose that environmental heterogeneity is central in this regard.

Acknowledgments We gratefully acknowledge the more than 60 individuals who have participated in collecting data and thinking about pollen and seeds. The School of Biological Sciences at the University of California at Irvine provided financial support to K. A. M. while Y. B. L. was supported by NSF grants BMS 75-14050, DEB 78-16798, BSR 8918478, and BSR 912065. Linda Joyce and the staff of the Forest Service's Rocky Mountain Research Station provided the climate data from the Manitou Experimental Forest. William Bowman, Dave Kelly, Walt Koenig, Victoria Sork, Alice Winn and one anonymous reviewers provided helpful suggestions for analyses and comments on our manuscript. All the work described in this manuscript complies with the current laws of the United States of America.

Open Access This article is distributed under the terms of the Creative Commons Attribution Noncommercial License which permits any noncommercial use, distribution, and reproduction in any medium, provided the original author(s) and source are credited.

\section{References}

Ashton PS, Givnish TJ, Appanah S (1988) Staggered flowering in the Dipterocarpaceae-new insights into floral induction and the evolution of mast fruiting in the aseasonal tropics. Am Nat 132:44-66

Bock CE, Lepthien LW (1976) Synchronous eruptions of boreal seedeating birds. Am Nat 110:559-571

Bodenham J, Stevens RE (1981) Insects associated with 2nd-year ponderosa pine cones, Larimer County and Boulder County Colorado. Southwest Nat 26:375-378

Cannon CH, Curran LM, Marshall AJ, Leighton M (2007) Beyond mast-fruiting events: community asynchrony and individual dormancy dominate woody plant reproductive behavior across seven Bornean forest types. Curr Sci 93:1558-1566

Curran LM, Leighton M (2000) Vertebrate responses to spatiotemporal variation in seed production of mast-fruiting Dipterocarpaceae. Ecol Monogr 70:101-128

Garcia LV (2004) Escaping the Bonferroni iron claw in ecological studies. Oikos 105:657-663
Hedlin AF, Yates HO III, Tovar DC, Ebel BH, Koerber TW, Merkel EP (1980) Cone and seed insects of North American conifers, U.S. Department of Agriculture Forest Service, Washington, DC

Herrera CM, Jordano P, Guitian J, Traveset A (1998) Annual variability in seed production by woody plants and the masting concept: reassessment of principles and relationship to pollination and seed dispersal. Am Nat 152:576-594

Iwasa Y, Satake A (2004) Mechanisms inducing spatially extended synchrony in mast seeding: the role of pollen coupling and environmental fluctuation. Ecol Res 19:13-20

Janzen DH (1976) Why bamboos wait so long to flower. Annu Rev Ecol Syst 7:347-391

Johnson DE (1998) Applied multivariate methods for data analysts. Duxbury, Pacific Grove

Keefover-Ring K, Linhart YB (2010) Variable chemistry and herbivory of ponderosa pine cones. Int J Plant Sci 171:293-302

Kelly D, Sork VL (2002) Mast seeding in perennial plants: why, how, where? Annu Rev Ecol Syst 33:427-447

Kelly D, Koenig WD, Liebhold AM (2008) An intercontinental comparison of the dynamic behavior of mast seeding communities. Popul Ecol 50:329-342

Klinkhamer PGL, de Jong TJ, Metz H (1997) Sex and size in cosexual plants. Trends Ecol Evol 12:260-265

Koenig WD, Knops JMH (1998) Scale of mast-seeding and tree-ring growth. Nature 396:225-226

Koenig WD, Knops JMH (2005) The mystery of masting in trees. Am Sci 93:340-347

Kon H, Noda T, Terazawa K, Koyama H, Yasaka M (2005) Evolutionary advantages of mast seeding in Fagus crenata. J Ecol 93:1148-1155

Krannitz PG, Duralia TE (2004) Cone and seed production in Pinus ponderosa: a review. West N Am Nat 64:208-218

Krouchi F, Derridj A, Lefevre F (2004) Year and tree effect on reproductive organisation of Cedrus atlantica in a natural forest. For Ecol Manage 197:181-189

Lamontagne JM, Boutin S (2007) Local-scale synchrony and variability in mast seed production patterns of Picea glauca. J Ecol 95:991-1000

Linhart YB (1988) Ecological and evolutionary studies of ponderosa pine in the rocky mountains. In: Baumgartner DM, Lotan JE (eds) Ponderosa pine: the species and its management. Washington State University Cooperative Extension Service, Pullman, pp 77-89

Linhart YB, Mitton JB (1985) Relationships among reproduction, growth-rates, and protein heterozygosity in ponderosa pine. Am J Bot 72:181-184

Lithner S, Jonsson KI (2002) Abundance of owls and bramblings Fringilla montifringilla in relation to mast seeding in southeastern Sweden. Ornis Svecica 12:35-45

Masaki T, Oka T, Osumi K, Suzuki W (2008) Geographical variation in climatic cues for mast seeding of Fagus crenata. Popul Ecol 50:357-366

McDonald PM (1992) Estimating seed crops of conifer and hardwood species. Can J For Res 22:832-838

Mitton JB, Linhart YB, Hamrick JL, Beckman JS (1977) Observations on genetic structure and mating system of ponderosa pine in Colorado front range. Theor Appl Genet 51:5-13

Mitton JB, Sturgeon KB, Davis ML (1980) Genetic differentiation in ponderosa pine along a steep elevational transect. Silv Genet 29:100-103

Monselise SP, Goldschmidt EE (1982) Alternate bearing in fruit trees. Hortic Rev 4:128-173

Mutel CF, Emerick JC (1992) From grassland to glacier: the natural history of Colorado and the surrounding region, 2nd edn. Johnson Books, Boulder 
Norton DA, Kelly D (1988) Mast seeding over 33 years by Dacrydium cupressinum Lamb. (Rimu) Podocarpaceae in New Zealand and the importance of economies of scale. Funct Ecol 2:399-408

Ostfeld RS, Keesing F (2000) Pulsed resources and community dynamics of consumers in terrestrial ecosystems. Trends Ecol Evol 15:232-237

Poncet BN et al (2009) The effect of climate on masting in the European larch and on its specific seed predators. Oecologia 159:527-537

Post E (2003) Large-scale climate synchronizes the timing of flowering by multiple species. Ecology 84:277-281

Salisbury EJ (1942) The reproductive capacity of plants. Bell, London

Sanguinetti J, Kitzberger T (2008) Patterns and mechanisms of masting in the large-seeded Southern Hemisphere conifer Araucaria araucana. Austral Ecol 33:78-87

SAS Institute (2008) SAS version 9.2. SAS Institute, Cary

Satake A, Iwasa Y (2002) The synchronized and intermittent reproduction of forest trees is mediated by the Moran effect, only in association with pollen coupling. J Ecol 90:830-838

Schauber EM et al (2002) Masting by eighteen New Zealand plant species: the role of temperature as a synchronizing cue. Ecology 83:1214-1225
Shepperd WD, Edminster CB, Mata SA (2006) Long-term seedfall, establishment, survival, and growth of natural and planted ponderosa pine in the Colorado front range. West J For 21:19-26

Silvertown JW (1980) The evolutionary ecology of mast seeding in trees. Biol J Linn Soc 14:235-250

Sork VL, Bramble J, Sexton O (1993) Ecology of mast-fruiting in three species of North American deciduous oaks. Ecology 74:528-541

Tapper PG (1996) Long-term patterns of mast fruiting in Fraxinus excelsior. Ecology 77:2567-2572

Waller DM (1993) How does mast-fruiting get started? Trends Ecol Evol 8:122-123

Webb CJ, Kelly D (1993) The reproductive-biology of the New Zealand flora. Trends Ecol Evol 8:442-447

Wich SA, Van Schaik CP (2000) The impact of El Nino on mast fruiting in Sumatra and elsewhere in Malesia. J Trop Ecol 16:563-577

Yang LH, Bastow JL, Spence KO, Wright AN (2008) What can we learn from resource pulses? Ecology 89:621-634

Yasaka M, Terazawa K, Koyama H, Kon H (2003) Masting behavior of Fagus crenata in Northern Japan: spatial synchrony and predispersal seed predation. For Ecol Manage 184:277-284 